\title{
Currículo e (de)colonialidade: a potência decolonial em escolas com baixo IDEB ${ }^{1}$
}

\section{Curriculum and (de)coloniality: the decolonial potency in low IDEB schools}

\section{Plan de estudio y (de)colonialidad: la potencia decolonial en escuelas con bajo IDEB}

\author{
Ruth Pavan ${ }^{2}$ \\ Sirley Lizott Tedeschi
}

DOI: http://dx.doi.org/10.20435/serie-estudos.v26i57.1538

\begin{abstract}
Resumo: O artigo, fruto de projeto de pesquisa com apoio do CNPq, pretende mostrar, por meio da análise de entrevistas com professoras e professores que atuam em escolas públicas com baixo Índice de Desenvolvimento da Educação Básica (IDEB), que há potência decolonial em escolas (des) classificadas pelas avaliações em larga escala como tendo baixa qualidade. Inicialmente, fazemos uma discussão do currículo e da colonialidade. Em seguida, trazemos as incursões metodológicas, com destaque para a escolha dos sujeitos e para o instrumento de coleta de dados, articulandoas com a concepção teórica, pautada em autores do campo crítico, sobretudo em autores da decolonialidade. Segue, então, a análise da pesquisa de campo. Por fim, apresentamos algumas conclusões, de caráter provisório, pois entendemos, juntamente dos autores e das autoras que trazemos neste artigo, que tanto o conhecimento quanto o currículo são campos dinâmicos, portanto, sem possibilidade de oferecer conclusões definitivas e fechadas. As falas analisadas das professoras e dos professores situam-se, ainda que de forma tênue, na perspectiva da denúncia, ao criticarem o racismo e o currículo oficial, mas também se situam na perspectiva das alternativas ao inserirem o contexto e a realidade dos alunos, vendo neles conhecimentos importantes a serem incluídos no currículo.
\end{abstract}

Palavras-chave: currículo; decolonialidade; escola.

Abstract: This paper, resulting from a research project supported by the CNPq, intends to show, through the analysis of interviews with teachers who work in public schools with a low Basic Education Development Index (IDEB), that there is decolonial power in schools (dis)classified by

\footnotetext{
${ }^{1}$ Esta é uma versão revisada do artigo apresentado no 20ㅇ Encontro Nacional de Didática e Prática de Ensino (primeira versão virtual), Rio de Janeiro, 2020.

2 Universidade Católica Dom Bosco (UCDB), Campo Grande, Mato Grosso do Sul, Brasil.

${ }^{3}$ Universidade Estadual de Mato Grosso do Sul (UEMS), Campo Grande, Mato Grosso do Sul, Brasil.
} 
large scale evaluations as having low quality. Firstly, we discuss the curriculum and coloniality. Secondly, we present the methodological incursions, with an emphasis on the selection of the subjects and the data collection instrument, articulating them with the theoretical conception, based on authors from the critical field, particularly, on authors of decoloniality. Then, the analysis of the field research follows. Finally, we present some provisional conclusions, since, like the authors mentioned in this paper, we understand that both knowledge and the curriculum are dynamic fields, therefore, there is no possibility of offering definitive and closed conclusions. Although in a tenuous way, the teachers' speeches pointed out a view of denunciation by criticizing racism and the official curriculum, but they also showed a perspective of alternatives by including the students' context and reality and seeing both as important knowledge to be included in the curriculum.

Keywords: curriculum; decoloniality; school.

Resumen: El artículo, resultado de un proyecto de investigación con apoyo del CNPq, pretende mostrar, por medio del análisis de entrevistas con profesoras y profesores que actúan en escuelas públicas con bajo Índice de Desarrollo de la Educación Básica (IDEB), que existe un potencial decolonial en escuelas (des)clasificadas por las evaluaciones a gran escala como de baja calidad. Inicialmente, hacemos una discusión del plan de estudio y de la colonialidad. Luego, traemos las incursiones metodológicas, con énfasis en la elección de los sujetos y en el instrumento de recolección de datos, articulándolas con la concepción teórica, basada en autores del campo crítico, pero sobre todo en autores de la decolonialidad. Sigue, entonces, el análisis de la investigación de campo. Finalmente, presentamos algunas conclusiones, de carácter provisorio, porque entendemos junto con los autores y autoras que traemos en este artículo, que tanto el conocimiento como el plan de estudio son campos dinámicos, por lo tanto, sin posibilidades de ofrecer conclusiones definitivas y cerradas. Los discursos analizados de las profesoras y profesores se sitúan, todavía de manera tenue, en la perspectiva de la denuncia al criticar el racismo y el plan de estudio oficial, pero también se sitúan en la perspectiva de alternativas al introducir el contexto y la realidad de los alumnos, viendo en ellos conocimientos importantes que deben incluirse en el plan de estudio..

Palabras clave: plan de estudio; decolonialidad; escuela.

\section{INTRODUÇÃO}

O currículo tem sido objeto privilegiado das políticas públicas. Entretanto, por mais que se pretenda impor um currículo único via Base Nacional Comum Curricular (BNCC), essa imposição é sempre uma impossibilidade. Além do que os Documentos Curriculares prescrevem, o currículo é vida, é potência, é criação, é invenção, é transgressão.

Da mesma forma, por mais que haja uma avaliação nacional padronizadora, classificatória, ranqueadora, desqualificadora, há, em todas as escolas, conhecimentos e práticas além daqueles previstos como relevantes para o aumento do Índice de Desenvolvimento da Educação Básica (IDEB). Há vários currículos nas escolas públicas. 
Com esse entendimento, o artigo, fruto de projeto de pesquisa com apoio do CNPq (Edital Produtividade 2017), pretende mostrar que há potência decolonial em escolas (des)classificadas pelas avaliações em larga escala como tendo baixa qualidade. Inicialmente, trazemos a discussão do currículo e da colonialidade. Em seguida, apresentamos as incursões metodológicas, com destaque para a escolha dos sujeitos e do instrumento de coleta de dados. Essas incursões metodológicas estão articuladas com a concepção teórica, que se pauta em autores do campo crítico, especialmente em autores da (de)colonialidade.

Posteriormente, fazemos a análise das entrevistas realizadas com professores que atuam em escolas com baixo IDEB. Argumentaremos que, apesar de essas escolas, segundo a avaliação em larga escala, aparecerem como escolas de baixa qualidade, há nelas professores preocupados em educar seus alunos indo além do currículo previsto e que, não raras vezes, desenvolvem práticas com indícios de (de)colonialidade.

Por fim, apresentamos algumas conclusões, de caráter provisório, pois entendemos, juntamente dos autores e das autoras que trazemos neste artigo, que tanto o conhecimento quanto o currículo são campos dinâmicos, portanto, sem possibilidade de apontar conclusões definitivas e fechadas.

\section{O CURRÍCULO E A (DE)COLONIALIDADE}

Pensar o currículo em sua articulação com a (de)colonialidade nos faz lembrar o processo de colonização que intentou impor, por meio de violência física e simbólica, os padrões epistemológicos, cosmológicos, políticos e sociais ocidentais. Trata-se de um processo articulado com os interesses econômicos europeus, isto é, centrado na expansão do capitalismo, com suas características de dominação e exploração. Com o fim do período colonial propriamente dito, os padrões de conhecer, poder, ser e viver impostos nesse período não foram extintos, mantendo-se e se atualizando permanentemente, o que é denominado de colonialidade. Portanto a colonialidade é um efeito da colonização (BERNARDINOCOSTA; GROSFOGUEL, 2016).

Conforme Quijano (2010, p. 84), a colonialidade é intrínseca ao poder capitalista: "sustenta-se na imposição de uma classificação racial/étnica da população do mundo como pedra angular do referido padrão de poder e opera em cada 
um dos planos, meios e dimensões, materiais e subjetivos". Ela está presente em todas as esferas e espaços, portanto, também nos currículos.

Ao procurar impor um modo único de conhecer, ser, viver e poder, a colonialidade torna-se central no processo de apropriação dos recursos materiais e simbólicos. Ela é a estratégia central do capitalismo, um instrumento de controle das relações sociais, pois se pauta na validação de um único modo de conhecer (o ocidental/moderno). Este modo de conhecer, articulado com as exigências do capitalismo, promove "[...] a medição, a externalização (ou objetivação) do cognoscível em relação ao conhecedor, para o controle das relações dos indivíduos com a natureza e entre aquelas em relação a esta, em especial a propriedade dos recursos de produção". (QUIJANO, 2010, p. 85). Esta forma de conhecimento que nasce no bojo do processo de colonização, "[...] como a única racionalidade válida e como emblema da modernidade" (QUIJANO, 2010, p. 86), pauta-se na classificação dos grupos humanos "[...] entre inferiores e superiores, irracionais e racionais, primitivos e civilizados, tradicionais e modernos" (QUIJANO, 2010, p. 86).

Essa classificação, construída no período colonial, mantém-se pela colonialidade e, segundo Gomes (2018), embora presente em todos os espaços e sujeitos, opera de forma mais contundente em alguns, com destaque para as escolas de educação básica e a produção científica. Nestes espaços, "[...] a colonialidade opera, entre outros mecanismos, por meio dos currículos" (GOMES, 2018, p. 227).

Porém, mesmo que nesses espaços a colonialidade opere de forma mais intensa por meio dos currículos, é também nesses espaços que há (maior) potência decolonial, que "[...] aponta para uma dimensão da resistência e reexistência política que vai além dos processos de independências e descolonizações que ocorrem nas Américas no início do século XIX e na segunda metade do século XX na África, Ásia e Caribe" (BERNARDINO-COSTA, 2018, p. 124).

Há, nos currículos, outros conhecimentos, sujeitos, formas de conhecer, modos de ser, viver e conviver, e, muitas vezes, sua presença potencializa a (de) colonialidade. Gomes (2018, p. 235) diz que “[...] só é possível descolonizar os currículos e o conhecimento se descolonizarmos o olhar sobre os sujeitos, suas experiências, seus conhecimentos e a forma como os produzem".

Ao decolonizar-se o olhar sobre o outro, valorizando-se outros conhecimentos e modos de produzi-los, colocando em xeque as hierarquias raciais, de gênero, crença, sexualidade etc., se está contribuindo para "[...] concluir o processo 
incompleto de descolonização, seja nos países latino-americanos, seja dos países africanos, asiáticos e caribenhos" (BERNARDINO-COSTA, 2018, p. 124).

Decolonizar o currículo implica questionar a suposta universalidade de qualquer conhecimento e modo de viver e ser, sobretudo o ocidental/moderno. $\mathrm{O}$ modelo ocidental/moderno não é universal; ele foi imposto como universal, mas trata-se de um modo muito particular de olhar para o mundo, para a diferença, para o outro. Um modo de olhar para o outro como inferior, incapaz, bárbaro, inculto, não civilizado. O universalismo moderno/ocidental é abstrato e pauta-se em "[...] um tipo de particularismo que se estabelece como hegemônico e se apresenta como desincorporado, sem pertencimento a qualquer localização geopolítica e desinteressado" (BERNARDINO-COSTA, 2018, p. 125). Os conhecimentos e os modos de ser e viver são todos particulares, pertencentes a um determinado grupo. Assim, mais do que em relações universais que tendem para a comparação e posterior (des)classificação e inferiorização, cabe pensar em relações horizontais, particulares e complementares.

Dessa forma, propomos discutir o currículo escolar no que denominamos neste artigo, com base em diferentes autores, de pensamento decolonial, distanciando-nos do universalismo abstrato que pretende tornar hegemônico um pensamento que é de um pequeno grupo. Intencionamos afirmar outros sujeitos, suas vivências, seus conhecimentos e modos de produzi-los (GOMES, 2018; BERNARDINO-COSTA, 2018, p. 126). Pretendemos afirmar um currículo decolonial.

Com base em Santos (1995), pode-se dizer que pensar em uma perspectiva de currículo decolonial implica fazer rupturas com os processos que contribuem com a produção de epistemicídios, por sinal, muito mais abrangentes que os genocídios. Os europeus eliminaram povos porque estes tinham conhecimentos estranhos, mas também eliminaram conhecimentos estranhos. Em decorrência dessa eliminação de conhecimentos, muitos povos também acabaram sendo eliminados. Nesse sentido,

[...] o epistemicídio foi muito mais vasto que o genocídio porque ocorreu sempre que se pretendeu subalternizar, subordinar, marginalizar ou ilegalizar práticas e grupos sociais que podiam ameaçar a expansão capitalista ou, durante boa parte do nosso século, a expansão comunista (neste domínio tão moderno quanto a capitalista); e também porque ocorreu tanto no espaço periférico, extra-europeu e extra-norte-americano do sistema mundial, como no espaço central europeu e norte-americano, contra os trabalhadores, os 
índios, os negros, as mulheres e as minorias em geral (étnicas, religiosas, sexuais). (SANTOS, 1995, p. 328).

Como já destacamos, o currículo escolar pode ser também um lugar de experiências decoloniais, portanto pode seguir um caminho contrário ao dos inúmeros epistemicídios, aceitando e problematizando as diferentes lógicas de produção do conhecimento, de aprendizagem e de modos de ser, viver e conviver. Nesse sentido, cabe "[...] considerar as iniciativas que foram pautadas na solidariedade e na cooperação, na subversão favorecida por práticas comunitárias e desobedientes. Por isso, qualquer proposta educacional terá que partir de uma escuta sensível [...]". (MIRANDA; RIASCOS, 2016, p. 570).

No entanto decolonizar o currículo e escutar sensivelmente os diferentes grupos e sujeitos não é uma tarefa fácil, já que, historicamente, o conhecimento que não era "[...] suscetível de ser apropriado era violentamente suprimido" (SANTOS, 2019, p. 71), o que significa que, nas colônias, como o Brasil, os epistemicídios foram muito maiores e continuam por meio da colonialidade. Houve e há, conforme o autor, muita violência epistêmica e injustiça cognitiva. A “[...] injustiça social global está assim intimamente ligada à injustiça cognitiva global, de modo que a luta pela justiça social global também deve ser uma luta pela justiça cognitiva global" (SANTOS, 2007, p. 5). Ainda segundo o autor, necessitamos de um pensamento pós-abissal (que pode ser visto como decolonial) para visibilizar o que, pelo processo de colonização, se tornou invisível em um abismo entre o tipo de conhecimento considerado importante e verdadeiro (moderno/ocidental) e os conhecimentos invisibilizados, irrelevantes (de indígenas, negros, populares...).

Como pretendemos argumentar, mesmo em escolas consideradas de baixa qualidade pelas avaliações em larga escala, apesar da colonialidade, que se expressa também em forma de epistemicídios e injustiça cognitiva, há possibilidades decoloniais. Antes de mostrá-las, descreveremos as incursões metodológicas.

\section{INCURSÕES METODOLÓGICAS}

O processo de pesquisa, quando envolve seres humanos, pode ser visto como uma "prática pedagógica", uma vez que, quando há "[...] interação de sujeitos diferentes e o contato com outra realidade, há aprendizagem e ensino de ambos os lados" (STRECK; ADAMS, 2014, p. 115); portanto envolve conhecimentos diferentes e reconhecimento. Em outras palavras, significa aceitar que a 
"[...] neutralidade da pesquisa é uma quimera" (COSTA, 2002, p. 153), pois o "[...] campo de pesquisa não é constituído por meros informantes, mas por pessoas que têm as suas maneiras de conhecer e produzir saberes que Ihes auxiliam no cotidiano, constrói-se outro entendimento das estratégias e da metodologia da investigação" (STRECK; ADAMS, 2014, p. 115).

Pensando dessa forma, nesta pesquisa, trabalhamos com professores e professoras de três escolas da Rede Pública Estadual localizadas na periferia de uma das capitais da região Centro-Oeste do Brasil. As escolas estão entre as dez com mais baixo IDEB na capital escolhida. Neste artigo, em função do espaço reduzido, traremos apenas a fala de alguns professores, de diferentes áreas de conhecimento, que nos possibilitem mostrar que há potência decolonial nessas escolas. Para manter o anonimato, os nomes das escolas e dos professores são fictícios.

A abordagem metodológica esteve em consonância com os estudos críticos e decoloniais de educação, reconhecendo a não dicotomia entre teoria e metodologia, assim como a existência de diferentes epistemologias. "O mundo continua mudando. [...] Há muitas e variadas formas de se compreender, explicar e conceber as coisas do mundo e da vida" (COSTA, 2002, p. 153). Desse modo, pode-se dizer que a análise aqui apresentada é uma das tantas possibilidades de lançar um olhar sobre o que dizem as professoras e os professores.

\section{A FALA DOS PROFESSORES E A POTÊNCIA DECOLONIAL}

Conforme já foi salientado, assim como Santos (2019), defendemos a pluralidade epistemológica, uma "ecologia de saberes" (p. 28). Reconhecer essa pluralidade, ainda que não seja o único, é um passo necessário para pensarmos a potência decolonial presente em escolas que, avaliadas a partir do pressuposto de que há só um conhecimento verdadeiro, são classificadas como sem qualidade. Mais do que desqualificar as escolas, urge-se considerar a diversidade de epistemologias e conhecimentos, para perceber a "[...] copresença de diferentes saberes e a necessidade de estudar as afinidades, as divergências, as complementaridades e as contradições que existem entre eles, a fim de maximizar a eficácia das lutas de resistência contra a opressão" (SANTOS, 2019, p. 28).

O professor Luciano, da escola Estrela, leciona as disciplinas de Matemática e Física. Quando fala sobre o processo de ensinar e aprender em sala de aula, afirma: 
Eu procuro chamar o aluno. Eu vejo que o aluno tem dificuldade, então, eu insisto nele. Às vezes, chegou de eu colocar a cadeira perto dele e falar 'vamos lá! Vamos fazer'! Ali, do lado. Porque às vezes, ali, ele se solta mais do meu lado do que lá na frente.

Em tempos em que a escola é vista como "[...] incompetente e em crise sempre que a adaptação à economia e à performance competitiva não [é] colocada no centro de sua missão" (LIMA, 2006, p. 27), um professor de Matemática e Física - disciplinas que são referência da ciência moderna/ocidental, geralmente apontadas como evidência da universalidade, neutralidade e imparcialidade - falar de proximidade e de sentar-se perto pode ser indício da potência decolonial. Isso porque a educação escolar decolonial é "[...] um processo teórico e prático que tem por finalidade a humanização da vida, do conhecimento e das relações sociais" (ESTERMANN; TAVARES; GOMES, 2017, p. 27).

De modo semelhante, a professora Luciana, também da escola Estrela, que leciona Arte, afirma que, no processo de seleção dos conteúdos a serem trabaIhados em sala de aula, considera o contexto dos alunos e seus conhecimentos:

Eu levo em consideração o conteúdo que eu tenho que trabalhar dentro das coisas que eles já trazem, assim, porque eles sugerem muitas coisas. [...] Sempre procurar conteúdo que eu vou poder associar com a realidade deles aqui. Eles gostam que eu vou trabalhar desenho, e eu relaciono com algo de que eles têm conhecimento, e não coisas que eles nunca viram e que eles não sabem. Então, sempre trazer algo da realidade deles e que eles já sabem.

Também, a professora Melissa, de Língua Portuguesa, da escola Sol, afirma:

Eu parto [...] da realidade dos meus alunos, da realidade da escola, para eu trabalhar, para fazer um currículo, porque o currículo não é aquela ementa que eles passam para a gente. O que eu faço é colocar dentro daquela realidade.

Pode-se observar que as professoras percebem que os alunos têm conhecimentos e que, ao levarem em conta esses conhecimentos e a realidade dos alunos, trabalhar os conhecimentos curriculares se torna mais significativo. A realidade dos alunos é cheia de conhecimentos, que as professoras, sem estabelecer hierarquias ou processos de classificação, colocam em relação para que haja a construção de outros conhecimentos. Ainda que de forma tênue, pode-se dizer que, para essas professoras, há diferentes conhecimentos. Talvez essas professoras nunca tenham ouvido falar em ecologia de saberes, mas cada uma a introduz, a seu modo, em 
sua aula, mostrando que há diferentes conhecimentos e que não há razão para eles serem desqualificados. Com isso, há uma possibilidade decolonial, que inclui a luta "[...] para a possibilidade de um modo-outro de vida" (WALSH, 2016, p. 72).

Um modo-outro de vida, para ser possível, supõe a desconstrução da decoIonialidade, que, como apontam Quijano (2010) e outros, assenta-se na hierarquia racial. Essa hierarquia, em alguns momentos, é colocada em xeque nas escolas, porque alunos e alunas se veem empoderados pela presença de uma coordenadora negra, como mostra a fala da mesma professora Luciana:

Você vê alunos com alguma brincadeira de mau gosto, principalmente, com meninos [negros], fazendo brincadeiras, meninas é mais relacionado com o cabelo. Mas você vê que muitos alunos já têm esse empoderamento, que enfrentam, que não estão nem aí e, quando eles já estão desse jeito, eles estão conscientes, ai eles não ligam, e os outros também param. Aí você percebe que, na verdade, era meio que uma implicância, era só para mexer com o outro, para tentar desestabilizar o outro ou algo assim. Mas, em geral, eu acho que aqui está nesse estado de se afirmar - "eu sou negro mesmo", "meu cabelo é cacheado" - e se valorizar. Tem muitos assim, e é interessante, eles veem uns aos outros e aí eles vão se afirmando também $e$, a coordenadora daqui também é negra e valoriza bastante, então, é bem legal assim. (Professora Luciana).

Novamente, há de se destacar que, nos tempos em que vivemos, nos quais a "[...] aprendizagem da humanidade, da solidariedade e do bem comum sucumbiram" (LIMA, 2006, p. 27) e há "[...] uma Pedagogia Contra o Outro" (LIMA, 2006, p. 27), a professora dizer que é legal ver seus alunos negros afirmarem sua identidade e não aceitarem a identidade produzida no período colonial é um indicativo da potência decolonial em escolas públicas com baixo IDEB. Pode-se dizer que a professora, ao valorizar a luta e o empoderamento de seus alunos negros, aproxima-se da "[...] opção decolonial [que] busca dar o devido valor à criação e à imaginação para estéticas outras" (BERGAMASCHI; MELO, 2018, 728). Embora os autores estejam se referindo à estética indígena, a estética afrodescendente também se situa no campo das outras estéticas, segundo a lógica da colonialidade, conforme a qual há uma forma estética superior: a ocidental/moderna. Podemos ver, na postura da professora, uma potência decolonial também, se aceitarmos que: "[...] decolonialidade é visibilizar as lutas contra a colonialidade a partir das pessoas, das suas práticas sociais, epistêmicas e políticas" (OLIVEIRA; CANDAU, 2010, p. 24). 
De modo semelhante, Luiz, professor de História e Filosofia da escola Lua, fala da importância de desenvolver a discussão racial em sala de aula, ainda que isso possa gerar conflitos, posto que os alunos já vêm com algumas práticas culturais vistas como normais pela cultura (da colonialidade) e, por isso, às vezes, não percebem que são racistas:

O preconceito cultural existente é muito latente dentro da nossa sociedade, e isso desemboca em sala de aula. Então, você trabalhar essa questão cultural dentro de sala de aula, às vezes, tem que ser um pouco conflitante, porque o aluno traz de casa, ele traz do meio familiar alguns aspectos que são culturais da própria família, como, por exemplo, o próprio preconceito racial. É normal às vezes, dentro de uma família, fazer piada com relação ao negro, ao índio, e o aluno traz isso para a sala de aula. (Professor Luiz, de História e Filosofia).

Além disso, assim como os outros professores já citados, para Luiz, é importante trazer o contexto, a realidade, a vivência dos alunos:

Primeiro, antes de mais nada, eu tento contextualizar, trazer para vivência, fazer sentido. Para que eu vou aprender isso? Então, eu tenho que trazer para o real e de acordo com a realidade de cada escola, porque cada escola é diferente da outra.

Novamente, percebe-se que o professor, assim como os anteriormente citados, parece distanciar-se da cegueira epistêmica, que "[...] impede que demandas culturalmente informadas e singularizadas sejam atendidas por arranjos espaciais [e curriculares] mais interessantes e complexos" (FREIRE-MEDEIROS; NAME, 2019, p. 116).

No caso de nossa pesquisa, é importante observar como os professores e professoras entrevistados apresentam um compromisso com o reconhecimento da importância do contexto do aluno e da aluna, sobretudo porque este contexto também produz conhecimento. Nesse sentido, podemos perceber que há várias possibilidades decoloniais, ou ainda, recorrendo a Santos (2007), possibilidades de diminuição do pensamento abissal e de aproximação com a justiça cognitiva. Trazendo-se o contexto, a realidade e os conhecimentos dos alunos, cria-se a possibilidade de "[...] combinar a sociologia das ausências e a sociologia das emergências, isto é, a denúncia e a alternativa, a crítica e a possibilidade" (SANTOS, 2019, p. 352). 
Como disse o professor Carlos, de Geografia, da escola Lua, é necessário trabalhar além do que está previsto na disciplina; é preciso desenvolver "[...] atividade extra, às vezes trabalhar com eles cidadania, ou mesmo entre as salas, o respeito entre os colegas". Esteban (2012, p. 589) aponta que "[...] o projeto de qualidade da educação vigente fundamenta-se em processos de exclusão que reafirmam padrões inacessíveis a todos e adequados a apenas um pequeno segmento da sociedade brasileira, assim guardando vínculos com fracasso escolar". Nesse sentido, o professor propor atividades que não estão previstas, desenvolvendo outras em tempos de controle pela avaliação em larga escala, também pode ser visto como potência decolonial.

Nossa preocupação nesta análise foi mostrar a potência decolonial em escolas com baixo IDEB. Com isso, ainda que de forma indireta, contribuímos também para mostrar que as escolas não têm um baixo IDEB pela falta de qualidade de seus alunos, nem de seus professores. Professores e alunos estão lidando com conhecimentos outros, conhecimentos sistematicamente ignorados pelas avaliações em larga escala, as quais privilegiam apenas um tipo de conhecimento. Concordamos, então, com Brighent (2017) quando afirma que as avaliações em larga escala são um projeto universalizante e colonialista. Assim, as "[...] notas baixas e os últimos lugares no IDEB é [sic] uma forma de dizer não à massificação das escolas. Portanto, enquanto persistir a prática universalista e colonialista, bem vindas notas baixas!" (BRIGHENT, 2017, p. 402).

\section{ALGUMAS CONCLUSÕES}

Ao finalizarmos o artigo, consideramos importante destacar que, nos tempos atuais de ataque sistemático ao que é público e, sobretudo, à educação pública, trazer a sua potência é uma atitude ética e política da qual não podemos prescindir. A resistência é cotidiana, sem trégua, não só no sentido de opor-se ao projeto da colonialidade, mas também no de mostrar outras possibilidades e alternativas: outras formas de poder, conhecer, ser e viver. Pensamos com Santos (2019, p. 352) que, atualmente, a mais séria deficiência do pensamento crítico eurocêntrico "[...] consiste em centrar-se exclusivamente na crítica e na denúncia. A ausência de alternativas só é intelectualmente convincente para quem não precisa delas existencialmente na sua vida diária". 
Nesse sentido, as falas analisadas das professoras e dos professores situam-se, mesmo que de maneira tênue, na perspectiva da denúncia ao criticarem o racismo e o currículo oficial, mas também se situam na perspectiva das alternativas ao inserirem o contexto e a realidade dos alunos, vendo neles conhecimentos importantes a serem incluídos no currículo.

Os professores e professoras, cada um/uma ao seu modo, apesar de condições adversas, preocupam-se em educar seus alunos, forjando cotidianamente rupturas com o currículo que impede o combate à opressão e à colonização dos alunos e alunas. Portanto pode-se dizer que há indícios de lutas decoloniais no currículo escolar e que há potência decolonial em escolas "sem" qualidade.

\section{REFERÊNCIAS}

BERGAMASCHI, Maria Aparecida; MELO, Dannilo Cesar Silva. Karaí Arandú na Bienal do Mercosul: educação guarani como possibilidade para uma estética decolonial. Revista Brasileira de Estudos da Presença, Porto Alegre, v. 8, n. 4, p. 719-49, 2018.

BERNARDINO-COSTA, Joaze. Decolonialidade, Atlântico Negro e intelectuais negros brasileiros: em busca de um diálogo horizontal. Sociedade e Estado, Brasília, v. 33, n. 1, p. 117-35, abr. 2018.

BERNARDINO-COSTA, Joaze; GROSFOGUEL, Ramón. Decolonialidade e perspectiva negra. Sociedade e Estado, Brasília, v. 31, n. 1, p. 15-24, abr. 2016.

BRIGHENTI, Clovis Antônio. Entre o universal e os específicos na construção da educação escolar indígena. Revista de Educação Pública, Cuiabá, v. 2, n. 62, p. 391-403, 2017.

COSTA, Marisa Vorraber. Uma agenda para jovens pesquisadores. In: COSTA, Marisa Vorraber (Org.). Caminhos investigativos II: outros modos de pensar e fazer pesquisa em educação. Rio de Janeiro: Dp\&A, 2002. p. 143-56.

ESTEBAN, Maria Teresa. Considerações sobre a política de avaliação da alfabetização: pensando a partir do cotidiano escolar. Revista Brasileira de Educação, Rio de Janeiro, v. 17, n. 51, p. 573-92, 2012.

ESTERMANN, Josef; TAVARES, Gomes; GOMES, Sandra. Interculturalidade crítica e decolonialidade da educação superior: para uma nova geopolítica do conhecimento. Laplage em Revista, Sorocaba, v. 3, n. 3, p. 17-29, set./dez. 2017. 
FREIRE-MEDEIROS, Bianca; NAME, Leo. Epistemologia da laje. Tempo e Sociedade, São Paulo, v. 31, n. 1, p. 153-72, abr. 2019.

GOMES, Nilma Lino. O Movimento Negro e a intelectualidade negra descolonizando os currículos. In: BERNARDINO-COSTA, Joaze; TORRES, Nelson Maldonado; GROSFOGEL, Ramon (Org.). Decolonialidade e pensamento afrodiaspórico. Belo Horizonte: Autêntica, 2018. p. 223-46. (V. 1).

LIMA, Licínio C. Escolarizando para uma educação crítica: a reinvenção das escolas como organizações democráticas. In: TEODORO, António; TORRES, Carlos Alberto (Org.). Educação crítica \& utopia: perspectivas para o século XXI. São Paulo: Cortez, 2006. p. 19-34.

MIRANDA, Claudia; RIASCOS, Fanny Milena Quiñones. Pedagogias decoloniais e interculturalidade: desafios para uma agenda educacional antirracista. Educação em Foco, Juiz de Fora, v. 21, n. 3, p. 545-72, set./dez. 2016.

OLIVEIRA, Luiz Fernandes; CANDAU, Vera Maria Ferrão. Pedagogia decolonial e educação antirracista e intercultural no Brasil. Educação em Revista, Belo Horizonte, v. 26, n. 1, p. 15-40, abr., 2010.

QUIJANO, Aníbal. Colonialidade do poder e classificação social. In: SANTOS, Boaventura de Souza; MENESES, Maria Paula (Org.). Epistemologias do Sul. São Paulo: Cortez Editora, 2010. p. 84-130.

SANTOS, Boaventura de Sousa. Para além do pensamento abissal: das linhas globais a uma ecologia de saberes. Novos Estudos-CEBRAP, São Paulo, n. 79, p. 71-94, nov. 2007.

SANTOS, Boaventura de Sousa. Pela mão de Alice: O Social e o Político na Pós-Modernidade. 12. ed. São Paulo: Editora Cortez, 1995.

SANTOS, Boaventura de Sousa. O fim do império cognitivo: a afirmação das epistemologias do Sul. Belo Horizonte: Autêntica Editora, 2019.

STRECK, Danilo R.; ADAMS, Telmo . Pesquisa Participativa, emancipação e (des) colonialidade. Curitiba: CRV, 2014. (V. 1).

WALSH, Catherine. Notas pedagógicas a partir das brechas decoloniais. In: CANDAU, Vera Maria (Org.). Interculturalizar, descolonizar, democratizar: uma educação "outra"? Rio de Janeiro: 7 Letras, 2016. p. 64-75. 


\section{Sobre as autoras:}

Ruth Pavan: Pós-Doutorado em Educação pela Universidade do Minho. Professora do Programa de Pós-Graduação Mestrado e Doutorado em Educação na Universidade Católica Dom Bosco(UCDB). E-mail: ruth@ucdb.br, Orcid: http://orcid.org/0000-0001-8979-1125

Sirley Lizott Tedeschi: Doutora em Educação pela Univesidade Católica Dom Bosco (UCDB). Professora da Universidade Estadual de Mato Grosso do Sul (UEMS).E-mail:tedeschils@gmail.com,Orcid:https://orcid.org/0000-0002-4557-8282

Recebido em: 28/03/2021

Aprovado em: 02/05/2021 